\title{
Quantile Mapping Bias Correction on Rossby Centre Regional Climate Models for Precipitation Analysis over Kenya, East Africa
}

\author{
Brian Ayugi ${ }^{1} \oplus$, Guirong Tan ${ }^{1, *}$, Niu Ruoyun ${ }^{2}$, Hassen Babaousmail ${ }^{3}$, Moses Ojara ${ }^{4}$, \\ Hanggoro Wido $^{5} \mathbb{D}$, Lucia Mumo ${ }^{1}\left(\mathbb{D}\right.$, Nadoya Hamida Ngoma ${ }^{1}$, Isaac Kwesi Nooni ${ }^{6}{ }^{(D)}$ and \\ Victor Ongoma ${ }^{1,7}$ (D)
}

1 Collaborative Innovation Center on Forecast and Evaluation of Meteorological Disasters/Key Laboratory of Meteorological Disaster, Ministry of Education, Nanjing University of Information Science and Technology, Nanjing 210044, China; ayugi.o@gmail.com (B.A.); mumolucia@gmail.com (L.M.); hamynads@gmail.com (N.H.N.); victor.ongoma@gmail.com (V.O.)

2 National Meteorological Centre, China Meteorological Administration, Beijing 100081, China; niury@cma.gov.cn

3 School of Computer and Software, Nanjing University of Information Science and Technology, Jiangsu, Nanjing 210044, China; baw.hassan12@gmail.com

4 Uganda National Meteorological Authority, Clement Hill Road, Kampala P.O. Box 7025, Uganda; ojacksmoz@gmail.com

5 Research and Development Center of Indonesia Agency for Meteorology Climatology and Geophysics, Jakarta 10720, Indonesia; wido_hanggoro@yahoo.com

6 School of Geographical Sciences, Nanjing University of Information Science and Technology, Nanjing 210044, China; nooni25593@alumni.itc.nl

7 School of Geography, Earth Science and Environment, University of the South Pacific, Laucala Campus Private Bag, Suva 61321, Fiji

* Correspondence: tanguirong@nuist.edu.cn

Received: 9 February 2020; Accepted: 11 March 2020; Published: 13 March 2020

check for updates

\begin{abstract}
This study uses the quantile mapping bias correction (QMBC) method to correct the bias in five regional climate models (RCMs) from the latest output of the Rossby Center Climate Regional Model (RCA4) over Kenya. The outputs were validated using various scalar metrics such as root-mean-square difference (RMSD), mean absolute error (MAE), and mean bias. The study found that the QMBC algorithm demonstrates varying performance among the models in the study domain. The results show that most of the models exhibit reasonable improvement after corrections at seasonal and annual timescales. Specifically, the European Community Earth-System (EC-EARTH) and Commonwealth Scientific and Industrial Research Organization (CSIRO) models depict remarkable improvement as compared to other models. On the contrary, the Institute Pierre Simon Laplace Model CM5A-MR (IPSL-CM5A-MR) model shows little improvement across the rainfall seasons (i.e., March-May (MAM) and October-December (OND)). The projections forced with bias-corrected historical simulations tallied observed values demonstrate satisfactory simulations as compared to the uncorrected RCMs output models. This study has demonstrated that using QMBC on outputs from RCA4 is an important intermediate step to improve climate data before performing any regional impact analysis. The corrected models may be used in projections of drought and flood extreme events over the study area.
\end{abstract}

Keywords: quantile mapping bias correction (QMBC); regional climate models (RCMs); Rossby Centre Regional Climate Model (RCA4); drought; flood; Kenya 


\section{Introduction}

Recently, the changes in the frequency and intensity of extreme events have led to severe climate-related disasters across many parts of the world. These extreme events (i.e., floods, droughts, and heat waves) have gained considerable attention from climate scientists and the general public due to their devastating impact on the ecosystem and different sectors of the economy. Thus, forecasting and monitoring of such events are crucial steps to ensure that the Malabo Goals 2025 and the 2030 Agenda for Sustainable Development of the Sustainable Development Goal 2 (SDG2) are met [1]. It is against this backdrop that climate information's availability and accuracy are essential for climate change assessment [2].

From a policy formulation perspective, global climate models (GCMs) and regional climate models (RCMs) are examples of datasets used in forecasting and projection studies. Additionally, model outputs from GCMs and RCMs are sometimes used as an input data sources in the prediction and projection of the extreme events. However, these model outputs are saddled with uncertainties that arise due to systematic and random biases relative to in-situ datasets [3,4]. For example, Cardell et al. [5] associated the random model error to intricate topography or atmosphere-biosphere transition along with large water bodies. In a different study, Allen et al. [6] linked systematic errors (model biases) to model coarser resolutions or parameterizations schemes.

Other studies (e.g., [7,8]) also reported considerable deviations from in-situ observations. Thus, within the context of these studies, end users are cautioned when generalizing results from these models' outputs. The models are of great interest to water resource planners and managers, who are required to periodically conduct a regional impact analysis to assess the impacts of climate change on watershed hydrology. Thus, to quantify the changes and predict extreme events against the backdrop of a warming climate, scientists and policy analysts alike have no other option than to use the existing GCM and RCM ensembles, despite the report of uncertainties in their assessments [2], based on data quality.

Meanwhile, different spatial downscaling and bias correction tools have been proposed and applied extensively to minimize these inherent errors or biases. Thus, to correct or minimize these biases or errors, scientists use two distinct spatial downscaling and bias correction tools, namely, statistical and dynamic downscaling methods.

In this study, we do not compare the advantages and disadvantages of these methods since extensive literature review shows that it is difficult to define the best approach, as the overall output performance of the two methods can reproduce the recent climate [9-11]. From literature, these two methods have been applied to downscale GCM to RCM [2].

Several RCMs based on dynamic downscaling are now available for many regions across the globe (IPCC, 2014). An example includes the RCM precipitation data sourced from Rossby Centre Climate Model outputs [12,13]. However, following the phenomenal study of Ahmed et al. [11], it is clear that the spatial resolution of the RCM for regional or local applications may not be high enough and may still contain some inherent errors. To use this type of climate data for present and future climate predictions, the two studies recommended bias corrections of RCM data to possibly remove the biases before their application. In parallel, this is particularly relevant for the African continent as well as its subregions, where the number of in-situ stations and data availability and quality have considerably declined and become less reliable [14].

Thus, to remove biases in RCM, recent studies $[3,4,15,16]$ have adopted statistical techniques to adjust RCM simulations and projections of climatic variables using different bias correction methods. Examples of the bias correction methods include the delta correction [17,18], linear transformation [19], local intensity scaling [20], power transformation [21], distribution mapping [22,23], and the quantile mapping bias correction (QMBC) [24,25], just to mention a few. The conclusions drawn from these studies suggest that the QMBC algorithm outperformed other methods [26-28]. It is important to note that $\mathrm{QMBC}$ is also referred to as quantile-quantile mapping [23], probability mapping, statistical downscaling, or histogram equalization [29]. 
The QMBC method is based on the hypothesis that climate biases that need to be corrected are unchanging; hence its features in historical data will persist into future projections [30,31]. Although this study acknowledges that QMBC technique has limitations [8,32], QMBC usage is widely preferred for impact analysis $[8,31,33,34]$.

Over the East Africa region, recent studies have reported the existence of biases in RCM and GCM datasets [35-37]. To illustrate this, Ayugi et al. [38] demonstrated the manifestation of systematic dry (wet) biases over regions of low (high) altitude characterized by arid and semi-arid lands (ASALs) or complex topography. Furthermore, the study reported that most mean spatial biases tend to follow the physiographic features in the study domain, which RCMs could not reproduce due to its coarse resolution $(\sim 50 \mathrm{~km})$ and physical parameterization. Despite the observed biases, few studies have attempted to correct systematic distributional biases relative to historical observations, and possible future simulations on the RCMs or GCMs. Many studies have, however, improved the quality of satellite-derived estimates using other techniques, such as Bayesian approach [39,40]. To improve the accuracy of projections of extreme events such as drought and flood over East Africa, better-performing RCMs and satellite datasets [35,38-41] ought to be further improved using correctional techniques to minimize possible biases and enhance the quality [30].

Thus, as a follow-up from Ayugi et al. [38], this study focuses on assessing the importance and performance of QMBC on model outputs over East Africa as an intermediate step before performing any regional impact analysis. This analysis is crucial from the sustainable planning for adaptation and mitigation of climate change and disaster risk reduction perspective. The objective of this study is to perform bias correction on the RCMs over Kenya, using QMBC before the assessment and projections of floods and droughts in the mentioned study domain. The remaining section of the paper is organized as follows: Section 2 highlights the data and methods used, while results and discussions are presented in Section 3. The last sections summarize the conclusion of the study with the possible recommendations.

\section{Materials and Methods}

\subsection{Study Area}

The region under study is situated in East Africa located along the celestial longitude $34^{\circ} \mathrm{E}-42^{\circ}$ $\mathrm{E}$ and latitude $5^{\circ} \mathrm{S}-5^{\circ} \mathrm{N}$ (Figure 1). Diverse physical features that play a significant role in climate modulation from one locality to another characterize this region [42]. For instance, the maximum thermal heat evidenced over the eastern and northeast parts that are predominantly arid and semi-arid lands (ASALs) and minimum temperatures over central regions are due to a high elevation point. Moreover, the uppermost (lowest) elevation with the altitude of $>5000 \mathrm{~m}(<0 \mathrm{~m})$ often leads to random uncertainties in climatic variables during the quantification process [6]. Consequently, the heterogeneous terrestrial classification influences socio-economic activity with a great inclination to rain-fed agriculture [43].

The region's climate is classified as tropical climate [44], with bimodal patterns of rainfall experienced during March to May (MAM) and October to December (OND) [45,46]. The months of May and November record the highest amount of rainfall across the study domain while March and October signify the onset of the seasons and record the least rainfall quantity $[45,47,48]$ in MAM and OND, respectively.

On the other hand, the highest temperature climatology is observed during January and February (JF), whereas the lowest is observed from June to September (JJAS) [49-51]. Generally, microclimate features over the study area are mostly regulated by the existence of unique geomorphology, while synoptic features are influenced by the interaction between atmosphere and hydrosphere within the lower troposphere. For example, the changes in Hadley circulation, which have an influence in the oscillation of the intertropical convergence zone (ITCZ), strongly regulate seasonal climate patterns over the study domain [52]. 


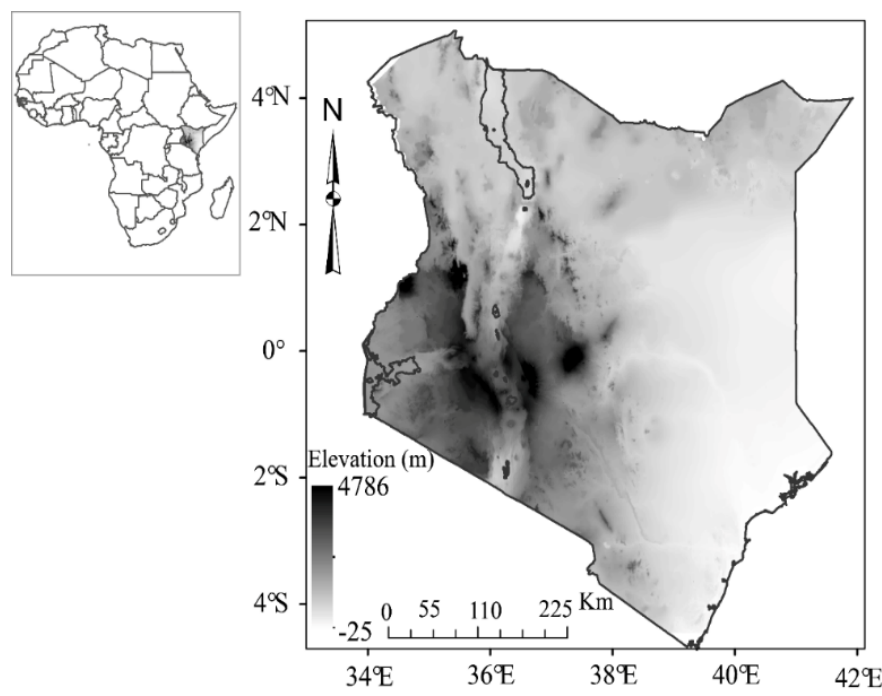

Figure 1. The study area $\left(34^{\circ} \mathrm{E}-42^{\circ} \mathrm{E}\right.$ and $\left.5^{\circ} \mathrm{S}-5^{\circ} \mathrm{N}\right)$ with topographical elevation $(\mathrm{m})$ in dark color. Enclosed is a map of the African domain with a study domain situated in the Eastern region marked with dark color.

\subsection{Data Description}

Biases in climate model simulation are commonly detected by validation (i.e., comparison with observation) through computation of mean and/or other complex analysis [53]. Several correction techniques have been proposed to rectify the existing biases in climate datasets $[17,19,21,23]$. The current study employed a QMBC algorithm to evaluate monthly RCM precipitation data sourced from Rossby Centre Climate Model outputs [12,54] and their respective mean multimodel ensemble (MME). They are as follows: Model for Interdisciplinary Research on Climate (MIROC5), Commonwealth Scientific and Industrial Research Organization (CSIRO), Institute Pierre Simon Laplace Model CM5A-MR (IPSL-CM5A-MR), Max Planck Institute Earth System Model at base resolution (MPI-ESM-LR) and European Community Earth-System (EC-EARTH). The RCMs have a horizontal grid increment of $0.44^{\circ}$ $\times 0.44^{\circ}(\sim 50 \mathrm{~km} \times 50 \mathrm{~km})$ with a historical coverage spanning from 1951 to 2005 for the simulations run while projections have temporal span from 2006 to 2100 for both RCP 4.5 and 8.5. The datasets were retrieved from the Deutsches Klimarechenzentrum GmbH (DRKZ) website (CERA-WDCC; https://cera-www.dkrz.de). Table 1 summarizes the information of each aforementioned model, giving their full names, native horizontal grid increment, and abbreviated name as used in this study.

Table 1. The description of the global climate models (GCMs) dynamically downscaled by Rossby Centre Regional Climate Model (RCA4) CORDEX.

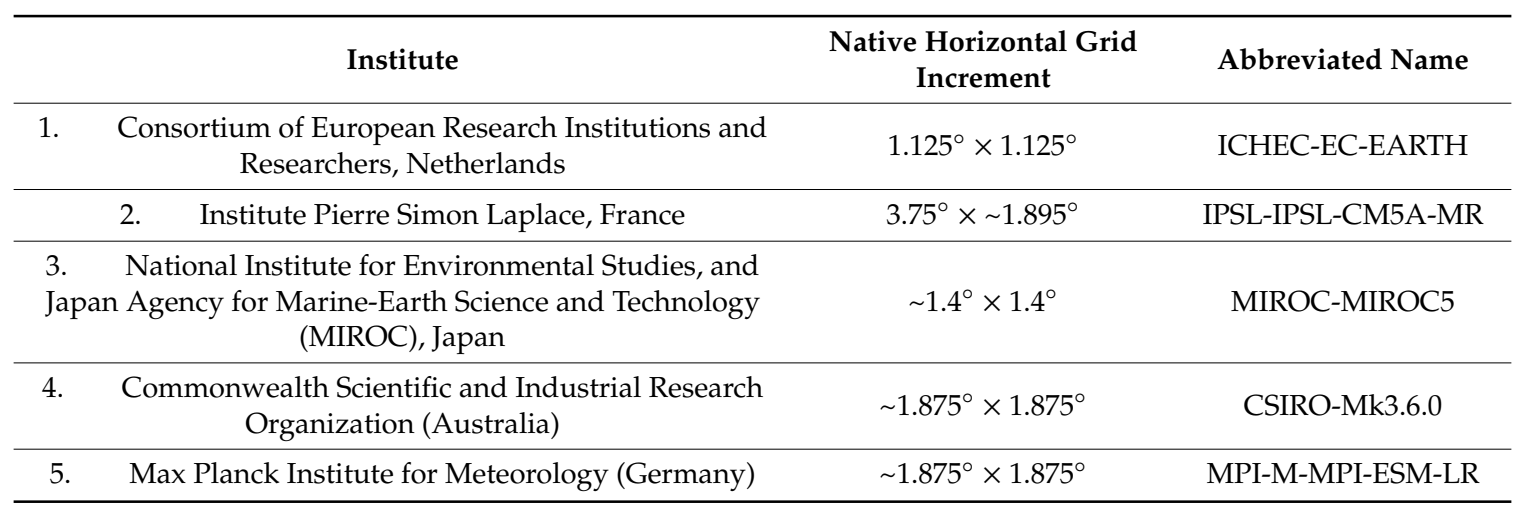

Climatic Research Unit (CRU TS4.02) datasets were employed as observed datasets during the validation period. Harris et al. [55] detailed more on this dataset. The CRU datasets utilized in this 
study have a temporal scale ranging from 1901-2017 and spatial coverage of $\sim 50 \mathrm{~km}$. The RCM datasets were evaluated in a recent study [38] that elucidated the listed models as better-performing from the ten GCMs that were dynamically downscaled based on the Rossby Center Regional Climate Model (RCA4). The datasets report glaring biases despite the skillful simulation of observed rainfall as compared to some models (Figure 2). Similar observations were made by Ayugi et al. [38]. Most models exhibit overestimation during OND season and underestimation throughout the MAM season (Figure 2). This has prompted the need for minimizing the biases in order to employ the models for drought and flood projections in a region that is vulnerable to the occurrence of extreme events.

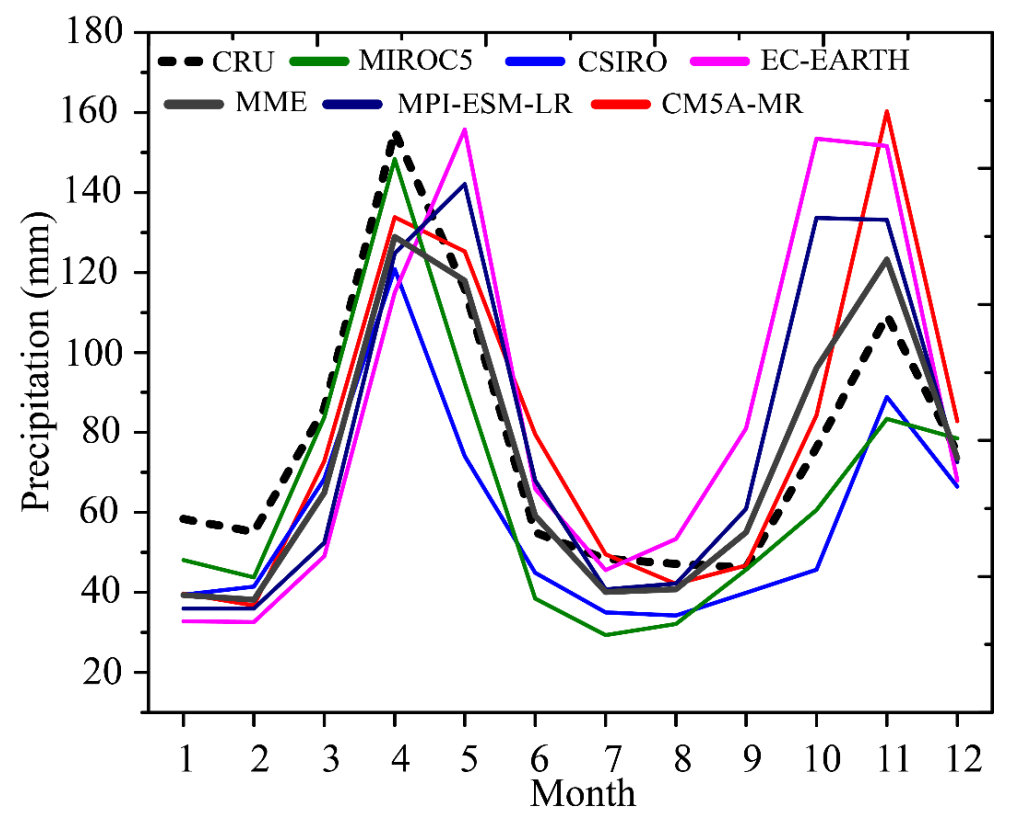

Figure 2. Annual precipitation cycle for the period 1951-2005 as simulated by five individual models of RCA4 over Kenya, depicting underestimation or overestimation of observed precipitation. Observation (black line) and multimodel ensemble (MME) mean (gray line) of regional climate models (RCMs) are displayed as well.

\subsection{Bias Correction Method}

The QMBC constructs cumulative distribution functions (CDFs) of the model and observations using a transfer function, which in turn translates the raw model outputs into corrected output. Thus, the CDF of the corrected model is transformed to match that of the observed datasets $[23,24,27]$. Mathematically, quantile mapping is constructed using Equation (1):

$$
\mathrm{y}=\mathrm{F}_{\mathrm{obs}}^{-1}\left(\mathrm{~F}_{\mathrm{RCM}}(\mathrm{x})\right)
$$

where $y$ is the corrected rainfall value, while $x$ is the value of precipitation to be corrected. On the other hand, $\mathrm{F}_{\mathrm{obs}}^{-1}$ is the inverse of the CDF of the observation, and $\mathrm{F}_{\mathrm{RCM}}$ is the CDF of the RCM used. The likelihood of detecting $\times(\mathrm{mm} / \mathrm{month})$ or less in the model is then transferred to the quantile of the observed CDF, matching very similar to observed probability. The QMBC was conducted using the available qmap package in the R software [26].

\subsubsection{Testing the Reliability of the Model Correction Approach}

Some methods are utilized in a bid to affirm the reliability of the model correction approach. The present study uses a split sample testing (SST) to examine how effective the QMBC algorithm is under different conditions. More information regarding this approach is presented by Klemeš [56]. 
Meanwhile, the SST technique involves splitting the data into two, preferably equal size, segments to use one for calibration and the other for validation.

In the current study, the SST approach was conducted by first training data for 29 years (1951-1979) to derive the biases field for monthly averages in the model and observed precipitation simulations. The monthly biased field was then used to correct independent RCMs during the following 26-year validation period (1980-2005). Additionally, projection estimates were corrected for the whole period, i.e., 2006-2100. The hypothesis for the SST technique is the temporal consistency of average errors. Figure 3 shows a summary flow of the SST approach used in this study.

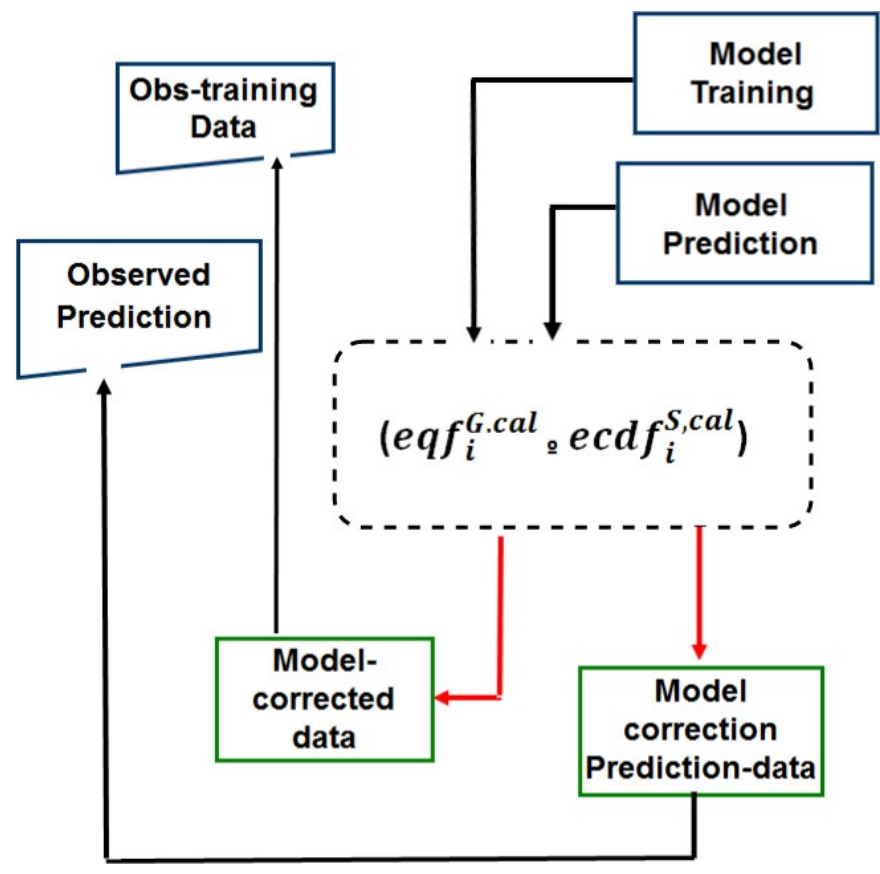

Figure 3. Flowchart of model bias correction procedure.

The transformational function for empirical quantile mapping distribution (ECDF) as highlighted in Equation (1) and shown in Figure 3, $\left(e q f_{i}^{G . c a l} \circ e c d f_{i}^{S, c a l}\right)\left(S_{t, i}^{\text {val }}\right)$, is explained as follows: eqf denotes empirical quantile function; the inverse of the ECDF and the operator $\left(^{\circ}\right)$ indicate the function's composition. $S$ and $G$ refer to the RCM and observed precipitation products, respectively; the superscript cal refers to calibration, while superscript val refers to validation. The flowchart shows the testing for the reliability of the correction algorithm, showing the two input data sources (observed and model-simulated) of a similar timespan being used as an input for the transform algorithm shown in the dotted section and explained in Equation (1). The output, which is model-corrected, is then used for the validation process, as described in Section 2.3.2. The model for future correction takes three files for bias correction, i.e., observed historical data, model-simulated historical data, and model-simulated future data. Here, observed and model-simulated data must be of the same period to get accurate results.

\subsubsection{Evaluation of Bias Correction Approach}

Evaluation of bias-corrected RCMs, historical simulations, and projection estimates were conducted using raw and bias-corrected RCMs related to the observed gridded precipitation datasets on a monthly and yearly basis. Statistical metrics such as the mean bias, mean absolute error (MAE), and customized RMSE to space and time scenario, were employed to compute their relationships. The mathematical formulas of the metrics mentioned herein are given in Equations (2)-(4). 


$$
\begin{gathered}
\text { Bias }=n^{-1} \sum_{i=1}^{n}\left(P_{M_{i}}-P_{R_{i}}\right) \\
M A E=n^{-1} \sum_{i=1}^{n}\left|P_{M_{i}}-P_{R_{i}}\right| \\
\text { RMSE }=\sqrt{n^{-1} \sum_{i=1}^{n}\left(P_{M_{i}}-P_{R_{i}}\right)^{2}}
\end{gathered}
$$

where $P_{M_{i}}$ is the model estimate for the considered data point $i, P_{R_{i}}$ is the observed value for the considered data point $i$, and $n$ is the length of the distribution of the data point being analyzed. For graphical displays, the study used empirical quantile mapping distribution (ECDF) and spatial maps to demonstrate the effectiveness of the QMBC algorithm.

\section{Results}

\subsection{Evaluation of Bias-corrected RCMs Simulations}

\subsubsection{Temporal Assessment}

Figure 4 presents ECDF analysis for five GCMs dynamically downscaled with the Rossby Centre Regional Climate Model (RCA4), as well as their ensemble average. Figure 4a,b represents March-May (MAM) season, Figure 4c,d shows October-December (OND), and Figure 4e,f shows annual before and after corrections, abbreviated as 'BC' and 'AC,' respectively. The MAM period experiences a substantial amount of rainfall in terms of magnitude, intensity, and frequency, thereby exhibiting large biases [57,58]. The observed biases were noted from recent studies $[35,38]$ that evaluated the performance of RCMs in simulating precipitation climatology over the larger Great Horn of Africa domain. The studies mentioned above mainly demonstrated underestimations of MAM rainfall in regions mostly associated with complex physiographical features. Compared to the observed datasets (CRU TS4.02; dotted line in Figure 4), it is apparent that the QMBC technique slightly improved the accuracy of most models and their ensemble after the corrections. Specifically, there were a few adjustments in mean bias, RMSD, and MAE in most models, with notable performance depicted by the CSIRO model during this season (Table 2).

In OND season (Figure 4c,d), many models show large biases before corrections that are mostly associated with orographic processes and related teleconnections, thus influencing rainfall variability and trends $[59,60]$. Most biases increased with an increase in rainfall magnitude with some models exhibiting considerable biases even after correction (Figure 4c,d and Table 2). In general, the results of this analysis show consistent improvement by most models during the OND season. The varying patterns of models, even after subjecting to the QMBC algorithm, show that the biases could be inherent from model errors, which can be either random or systematic.

Model bias correction at annual level (Figure 4e,f), however, showed upgrading by most models, most especially the EC-EARTH and CSIRO. Still, despite the corrected model, underestimation of annual rainfall continues to persist even in the corrected model output. The persistent biases in Figure 4e,f (AC) could be associated with dry biases originating from the ASAL regions and characterized by moisture outflow over the study region [36,38]. In addition, the high underestimation of the wet season (MAM; Figure 4a,b) could have contributed to an overall underestimation of annual rainfall, despite the correction. 


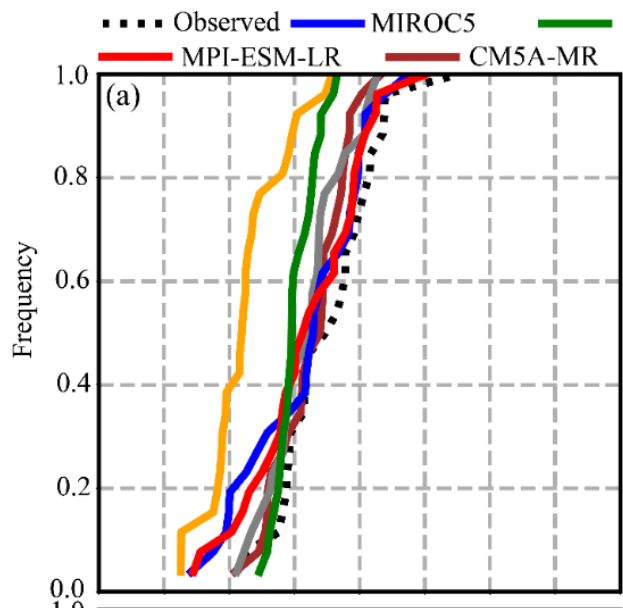

MME $=$ EC-EARTH $=$ CSIRO
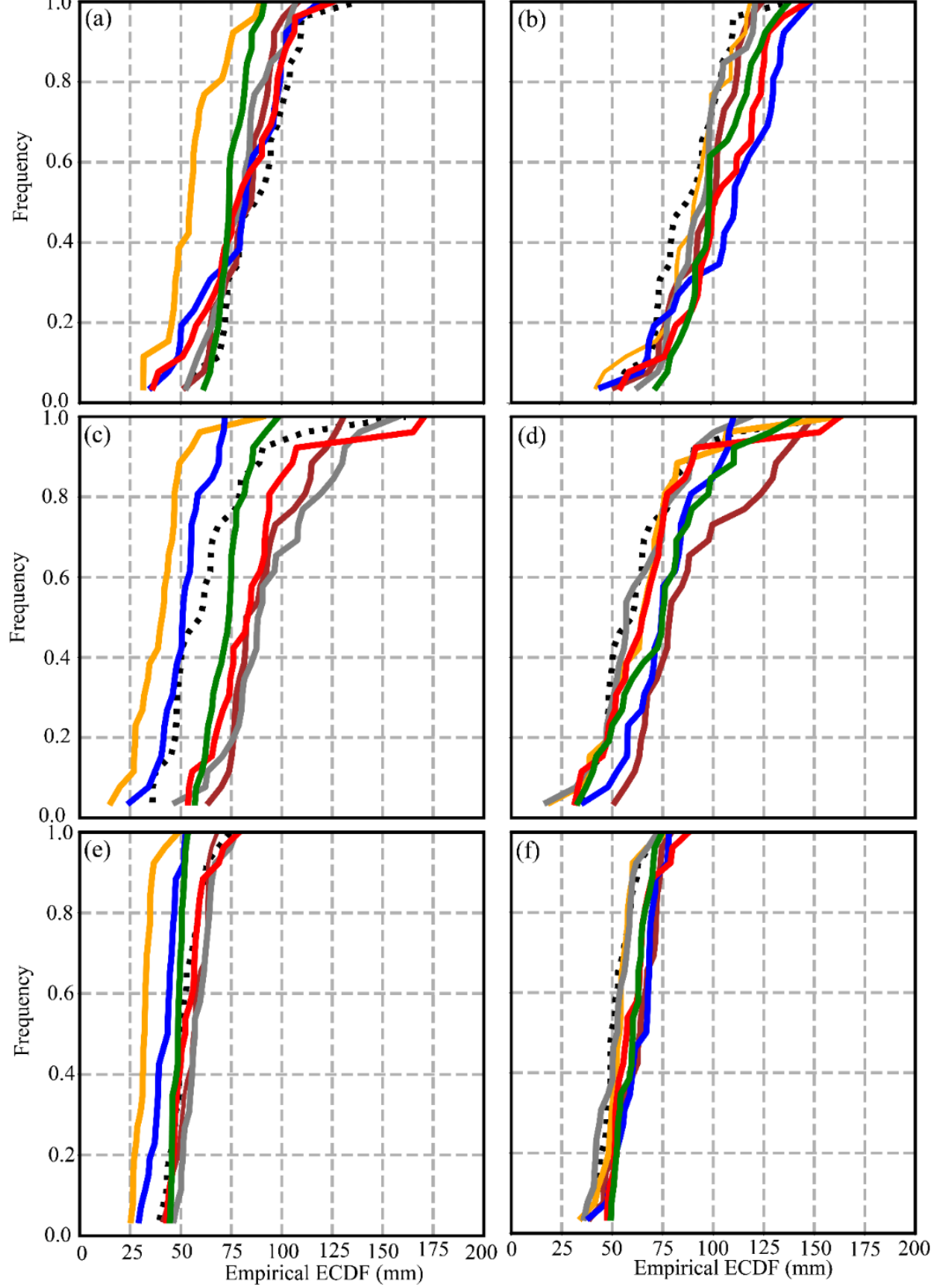

Figure 4. Empirical quantile mapping distribution (ECDF) plots for five global climate models (GCMs) dynamically downscaled with the Rossby Centre Regional Climate Model (RCA4), as well as their ensemble average. (a,b) represents March-May (MAM) season, (c,d) shows October-December (OND), and $(\mathbf{e}, \mathbf{f})$ shows annual before and after corrections, abbreviated as 'BC' and 'AC,' respectively.

The notable biases by most models concur with a study by Kimani et al. [40] that similarly observed the bias dependence on rainfall amounts over a larger domain of East Africa using satellite-derived precipitation estimates. Eden et al. [61] and Cannon et al. [8] demonstrated that persistent biases even after model corrections are as a result of systematic errors in model outputs from diverse sources. For instance, these studies reported that field-observed biases originate from either unrealistic response to climate forcing or unpredictable internal variability that differs from observations. Hence, such biases cannot be corrected by most correction algorithms. The conclusions from these studies highlighted that 
only errors in convective parameterizations and unresolved subgrid-scale orography could be corrected using univariate statistical bias correction techniques like QMBC employed in the present study.

Table 2. Comparison of different RCMs using summary statistics against the observed data for the validation. The effect of bias correction on other statistics, i.e., RMSD, MAE, and bias.

\begin{tabular}{cccccccc}
\hline \multicolumn{7}{c}{} & \multicolumn{7}{c}{ RCMs Validation } \\
\cline { 2 - 7 } MAM & RCMs & Mean Bias & Bias (bc) & RMSD & RMSD (bc) & MAE & MAE (bc) \\
\hline & CM5A-MR & 6.52 & -8.54 & 24.38 & 27.84 & 20.95 & 22.42 \\
& CSIRO & 31.98 & $-\mathbf{2 . 5 8}$ & 40.20 & $\mathbf{2 6 . 9 3}$ & 32.75 & $\mathbf{2 2 . 1 6}$ \\
& EC-EARTH & 8.57 & $-\mathbf{6 . 0 4}$ & 25.33 & 25.11 & 18.46 & 16.96 \\
& MIROC5 & 8.48 & -17.31 & 29.21 & 47.51 & 24.21 & 37.61 \\
& MPI-ESM-LR & 8.11 & 19.66 & 28.75 & 36.20 & 20.94 & 29.98 \\
& MME & 12.73 & -16.28 & 23.61 & 31.12 & 18.77 & 24.37 \\
\hline \multirow{6}{*}{ OND } & CM5A-MR & -26.68 & -27.32 & 38.11 & 46.49 & 31.86 & 36.77 \\
& CSIRO & 24.23 & $\mathbf{0 . 5 3}$ & 38.22 & 40.82 & 27.92 & 28.38 \\
& EC-EARTH & -31.01 & $\mathbf{2 . 9 0}$ & 47.75 & 36.69 & 40.22 & $\mathbf{2 6 . 1 8}$ \\
& MIROC5 & 13.15 & -15.29 & 30.81 & 37.88 & 22.69 & 31.91 \\
& MPI-ESM-LR & -22.52 & -6.70 & 45.53 & 44.54 & 34.80 & 31.87 \\
Annual & MME & -8.56 & -14.64 & 28.58 & 42.04 & 22.15 & 32.48 \\
\hline & CM5A-MR & -3.49 & -11.53 & 11.07 & 17.85 & 9.11 & 14.46 \\
& CSIRO & 20.94 & $-\mathbf{1 . 3 7}$ & 22.94 & $\mathbf{1 3 . 2 9}$ & 20.56 & $\mathbf{9 . 5 5}$ \\
& EC-EARTH & -6.14 & $\mathbf{1 . 3 8}$ & 12.68 & 15.36 & 10.64 & 11.07 \\
& MIROC5 & 10.59 & -11.21 & 15.77 & 19.05 & 12.23 & 16.00 \\
& MPI-ESM-LR & -1.58 & -8.93 & 8.92 & 14.99 & 6.66 & 11.14 \\
& MME & 3.89 & -9.60 & 9.23 & 16.09 & 7.04 & 12.89 \\
\hline
\end{tabular}

Bold values denote models that exhibited notable improvements.

Nevertheless, Teng et al. [62] proposed a mitigation measure of enhancing the quality of the datasets that could not be corrected on the first attempt by further calibrating the postprocessing corrections on adequately long historical records. A summary of the performance of the bias correction method during the wet season and annually is shown in Figure 5. The results show noteworthy improvement by most models during the MAM season as compared to OND. It is worth mentioning that CM5A-MR had the least improvement during OND, while EC-EARTH reveals considerable enhancement during the same season.

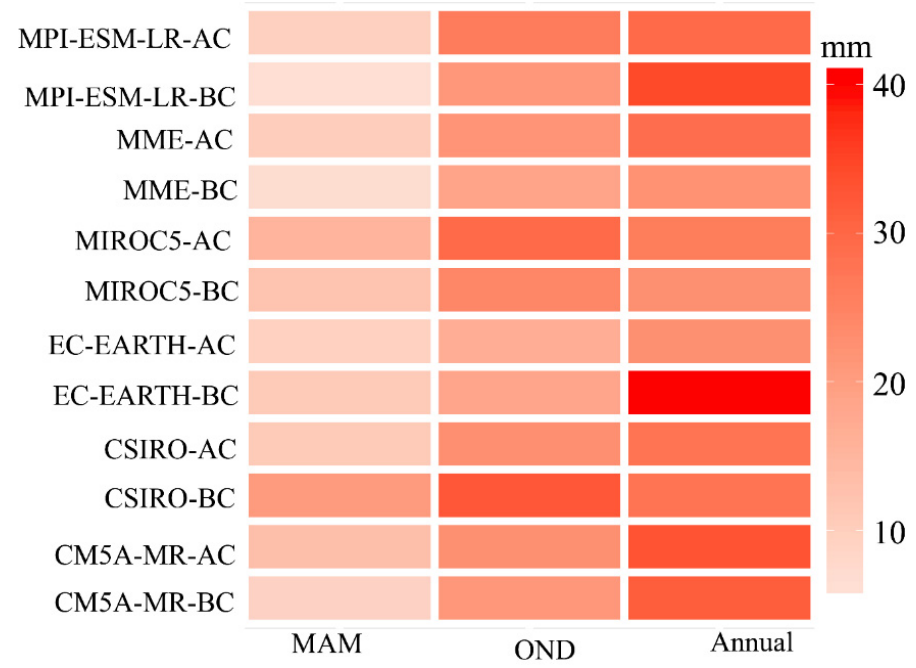

Figure 5. Heat plot of monthly and annual mean absolute error (MAE) relative to each model during (1980-2005). A lighter color denotes better results while deep color represents unsatisfactory bias-corrected value during the wet months and on a yearly basis. 


\subsubsection{Spatial Bias Correction Estimates}

Figure 6 presents spatial patterns of mean annual root-mean-square difference (RMSD) during the period 1980-2005 derived from five RCMs as well as their ensemble average. The corresponding bias-corrected (abbreviated as AC) RCMs from Rossby Centre Regional Climate Model (RCA4), as well as the corrected multi-model ensemble (MME) are also shown in the plots. The models were corrected relative to the climatic research unit (CRU TS4.02) datasets. The spatial plots depict regions of underestimations and overestimations and respective areas of enhancement after the employment of the quantile mapping technique.
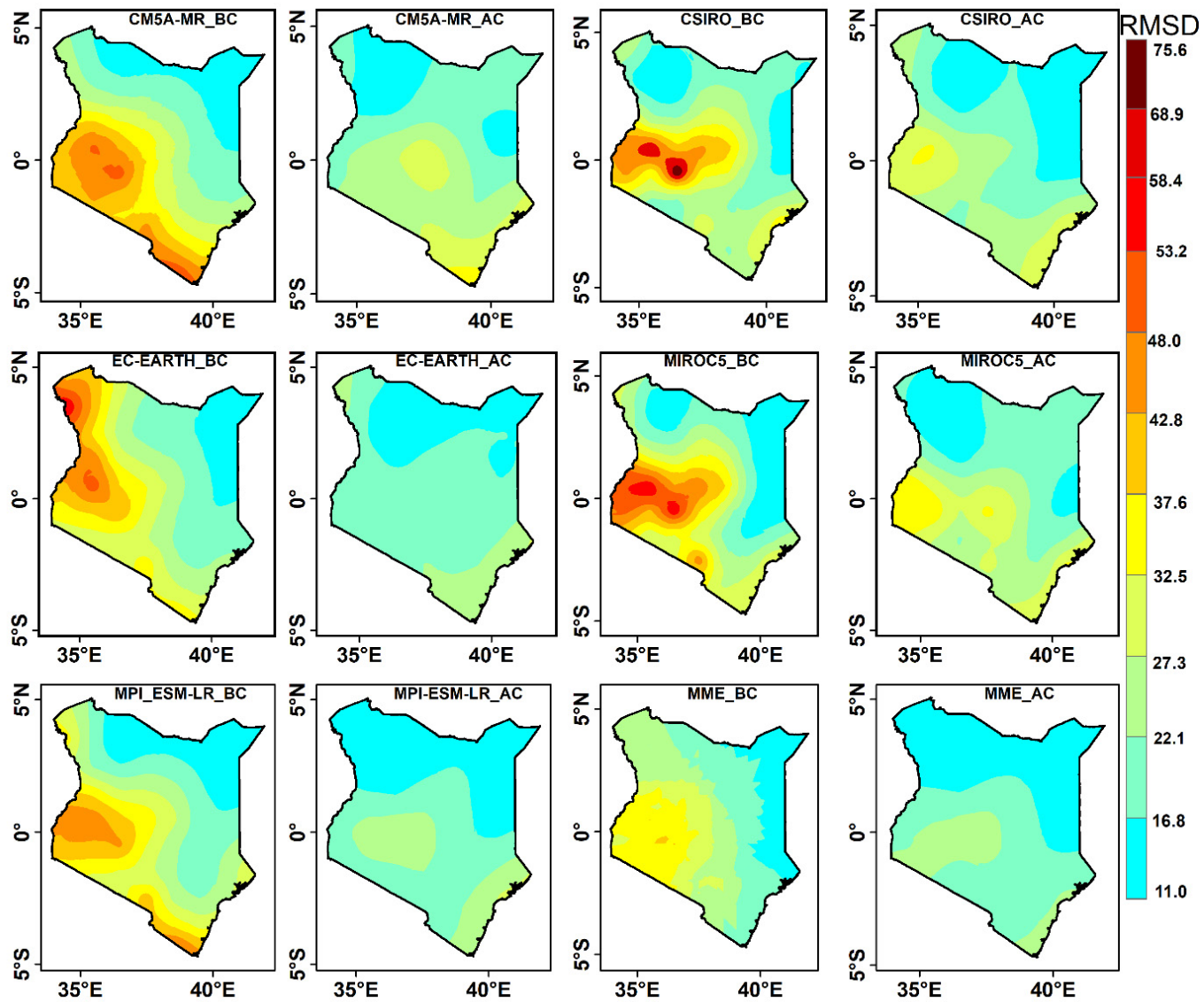

Figure 6. The spatial pattern of RMSD (before correction (BC) and after correction (AC)) for the period 1951-2005, considering five global climate models (GCMs) dynamically downscaled with the Rossby Centre Regional Climate Model (RCA4), as well as their ensemble average.

It is apparent that significant biases simulated by the models corresponded with the regions that experience the highest rainfall amount. This agrees with observed west-to-east gradient, demonstrating heavier to lighter rainfall events over the study domain [39,41]. As a result, the highest RMSD is noted in central and western sections of the study area, while lowest biases $(<22.1 \mathrm{~mm} / \mathrm{month})$ are exhibited in the eastern and northwestern areas.

Further analysis was conducted to evaluate how the correction algorithm improves the model projections under RCP4.5 'stabilization scenario' and RCP8.5 'business as usual scenario'. Figure 7 provides seasonal and annual spatial patterns of mean rainfall based on the multimodel ensemble (MME) of five RCMs. The model's simulations were corrected using observed data, while model projections entailed the simulations and observations as an input variable. Historical simulations after corrections showed improvement in some regions across various timescales to resemble the spatial patterns of observed data. Systematic biases appeared to be reduced in regions that depicted strong biases, especially during the MAM rainfall season. 

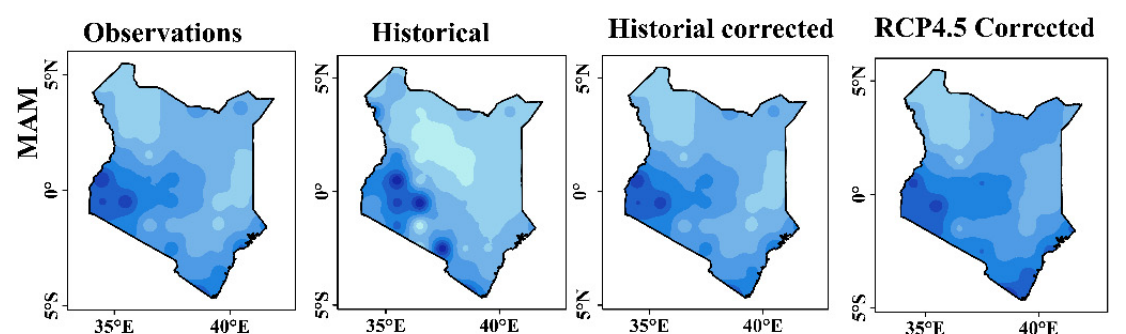

RCP8.5 Corrected
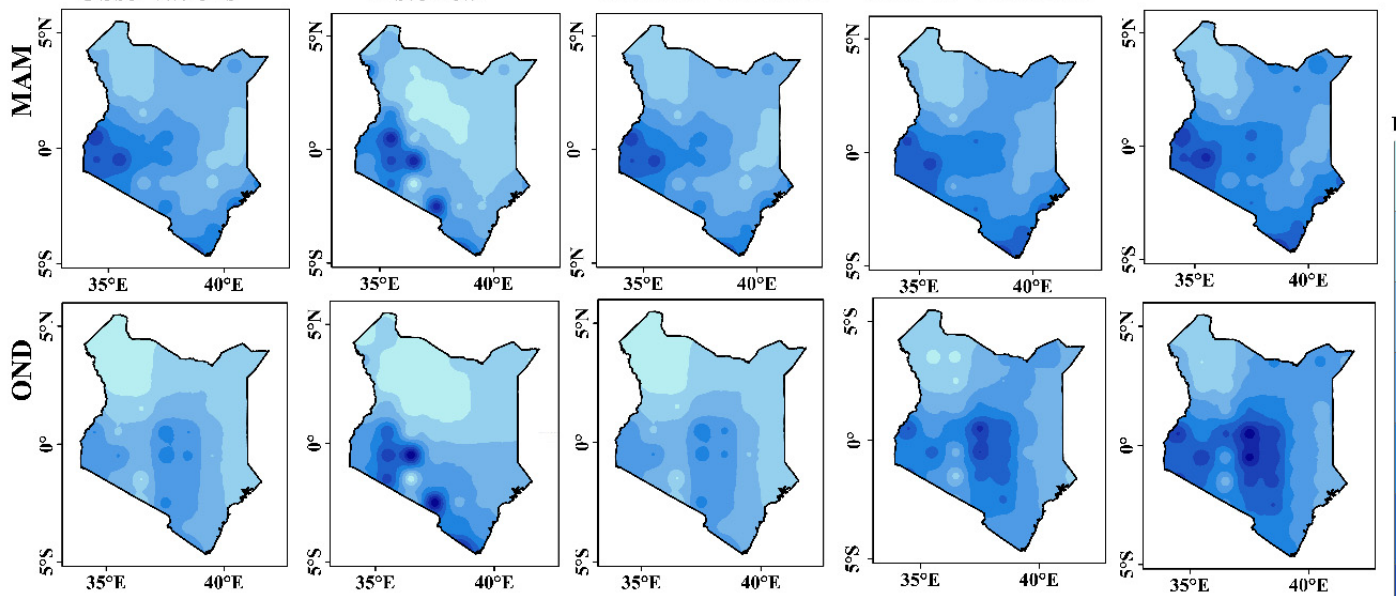

Rainfall (mm)

37.1

62.7

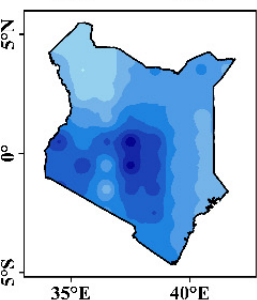

88.3
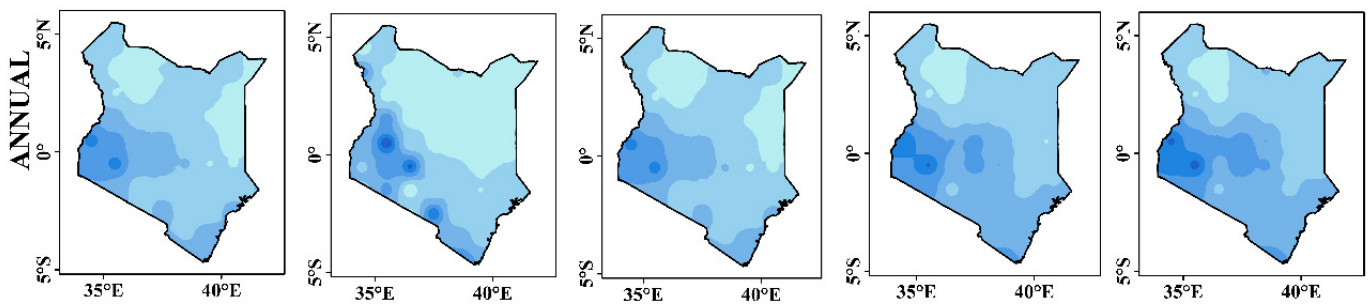

113.9

139.5

165.1

190.7

Figure 7. The seasonal and annual spatial patterns of mean rainfall for observed, simulated, simulated corrected, and model-corrected projections based on MME of five global climate models (GCMs) dynamically downscaled with the Rossby Centre Regional Climate Model (RCA4).

Moreover, there was strong evidence of improvement in both projections under medium emissions and strong emission scenarios in all the seasons. However, the regions characterized by complex topography tend to exhibit unsatisfactory reductions in biases, especially during the OND season. For instance, the model corrected under RCP8.5 depicts strong wet biases over central and western regions as compared to other timescales. Interestingly, the algorithm tends to show robust performance during the mean annual cycle that exhibits reduced rainfall occurrence.

These results agree with recent reports over broader study domains that have shown decreasing trends in rainfall patterns towards the end of 20th century $[45,47,48,57]$. Further, these studies demonstrate continued declining annual rainfall trends for different future scenarios over the study domain [63-65]. On the contrary, the observed increment patterns during the OND season concur with studies that have reported overestimations of OND, also referred to as 'short rains' over the study region [65-67]. Yang et al. [57] highlighted the aspect of challenges associated with simulations of atmosphere-ocean-monsoon interaction over the East Africa region as the primary cause of observed bias in models during OND and MAM projections. According to Funk et al. [68], the warming of the western Indian Ocean continues to play a significant role in simulated and projected patterns during the seasonal rainfall cycle.

\section{Discussion}

Based on ECDF analysis, the majority of the models show little improvement after correction during local wet seasons. For example, the mean absolute error (MAE) was generally large in MME-AC ( $24 \mathrm{~mm} / \mathrm{month}$ ) as compared to MME-BC (18.77 mm/month) (Table 2) for the MAM season. Interestingly, CSIRO and EC-EARTH show a remarkable enhancement during the wet months, as compared to other models that exhibited variations from one month to another. Overall, these results show that the algorithm slightly improved the model accuracy with some unique variation based on the magnitude of rainfall experienced over the study domain. For instance, there are large incidences of biases noted in May as compared to model underestimations during March and April (Figure 4). 
Nevertheless, most models show improvement after correction across the diverse timescales. For example, remarkable improvement is exhibited during the MAM season as compared to OND (Figure 5). It is worth noting that CM5A-MR had the least improvement during the OND, while EC-EARTH demonstrates substantial improvement during the same season. This confirms the need to improve the models before employing them for climate change impact studies [69]. Teleconnection patterns responsible for influencing the rainfall during the OND are likely to be amplified during the 'business as usual' model. This scenario could explain the systematic biases that are persistent in models even after the corrections. This calls for a cautious view of the possible limitations of correction techniques during the future projections [8] and possible adoption of more robust approaches, as proposed by Pielke et al. [70].

The observed values of RMSD (Figure 6), are mostly as a result of complex terrains such as high-altitude topographies. The central and western parts of Kenya have a varying topography explained by the presence of mountains like Mount Kenya and Mount Elgon, respectively. The areas are generally wet and humid, explained by large water bodies, notably Lake Victoria. As a result, most models exhibited acceptable performance after corrections, with EC-EARTH, MPI-ESM-LR, and MME demonstrating exemplary improvement as compared to other models. The results concur with a recent study that noted a linear relationship between increased rainfall values and subsequent increase of systematic uncertainties [40]. The overall monthly reduction in RMSD after correction ranged between 11.0 and $27 \mathrm{~mm} /$ month.

Overall, the QMBC can reasonably improve the models under different scenarios and timescales, hence it is relevant for correcting RCM outputs. Its application can, in effect, minimize possible biases, thereby making it suitable for the evaluation of extreme events such as drought and flood that continue to pose a threat to livelihoods and socio-economic infrastructure over the study domain. However, the existence of uncertainties even after corrections presents a challenge for the full recommendation of this approach as the most suitable. The performance of the algorithm in enhancing the quality of model data affirms the view of Ehret et al. [71]. To illustrate this view, the study pointed out the possibility of less value added to models after corrections in situations of complex modeling chain when considering other sources of uncertainties [72]. This was equally echoed in climate forum paper that questioned the need for regional climate downscaling [73]. Going forward, recent studies [73-75] have proposed a more robust approach evaluating impact analysis of extreme events. The method, which is known as bottom-up, resource-based vulnerability approach, is a more inclusive way of assessing risks, including the ones of climate variability and climate change.

\section{Conclusions}

The current study examined the effectiveness of quantile mapping bias correction on Rossby Center Regional Climate Models (RCA4) for drought and flood analysis. The study is a follow-up to the study by Ayugi et al. [38] on the recent assessment of the performance of RCA4 models over the study domain, which elucidated the existence of unsystematic and systematic biases in the better-performing models across the region. Thus, the current study was conducted within this backdrop. Correction to both mean annual and seasonal variance was conducted by employing the split sample testing (SST) approach. The correction was performed by first training data for 29 years (1951-1979) to derive a biases field for monthly averages in the model and observed precipitation simulations. The monthly biased field was then used to correct independent RCMs during the next 26-year (1980-2005) validation period. The models corrected are as follows: MIROC5, CSIRO, IPSL-CM5A-MR, MPI-ESM-LR, EC-EARTH, and MME.

Broadly, RCM simulations depict notable biases that are mostly associated with regions of complex terrains such as high-altitude or wet, humid regions within the study area. The QMBC demonstrates varying performance from one model to another on both spatial and temporal scales. However, most models exhibit consistent improvement after corrections on both seasonal and annual timescales. Specifically, the models EC-EARTH and CSIRO portray exemplary improvement as compared to 
other models. On the other hand, the model CM5A-MR model shows weak enhancement across various timescales, i.e., MAM and OND. The models showing persistent unsatisfactory improvement after employing correction approaches should be utilized with caution due to the existence of hidden nonlinearity and complex dynamical processes that are uncorrectable. The corrected models can be used for projections of extreme events, drought, and flood over the study area. The outputs will aid in appropriate policy formulation for effective and reliable adaptation techniques. The study, however, recommends the employment of the most robust approach of bottom-up, resource-based vulnerability technique in dealing with complexities of extreme events in the wake of global warming and changing climate. Recent studies [73-75] have detailed more information regarding this approach.

Author Contributions: Conceptualization, B.A., M.O., V.O.; methodology, H.B., and B.A.; software, H.W.; validation, L.M., H.B., and B.A.; formal analysis, B.A and G.T; investigation, G.T., H.B., V.O., and B.A.; resources, G.T., N.R.; data curation, B.A. and N.H.N.; writing-original draft preparation, B.A. and I.K; writing-review and editing, G.T., V.O., I.K.N., and B.A.; visualization, L.M., H.B., H.W., and B.A.; supervision, G.T.; project administration, G.T., B.A., and N.R.; funding acquisition, G.T. and N.R. All authors have read and agreed to the published version of the manuscript.

Funding: National Key Research and Development Program of China (2018YFC1507703\&2016YFA0600702), National Natural Science Foundation of China (41575070 and 41575085) supported this work.

Acknowledgments: The authors acknowledge Nanjing University of Information Science and Technology (NUIST) for providing a favorable environment and meeting infrastructural needs for conducting research. Special appreciation to all data centers for availing data to use for evaluation studies. The lead author is grateful to NUIST for granting him a scholarship to pursue $\mathrm{PhD}$ studies. The anonymous reviewers are highly appreciated for the great input that led to the massive improvement of this manuscript.

Conflicts of Interest: In a unanimous agreement, all authors declare no conflict of interest in the present study.

\section{References}

1. FAO. The State of Food Security and Nutrition in the World. Safeguading against Economic Slowdowns and Downturns; FAO: Rome, Italy, 2019.

2. IPCC. Climate Change 2014: Synthesis Report; Contribution of Working Groups I, II and III to the Fifth Assessment Report of the Intergovernmental Panel on Climate Change; Core Writing Team, Pachauri, R.K., Meyer, L.A., Eds.; IPCC: Geneva, Switzerland, 2014; 151p.

3. Christensen, J.H.; Boberg, F.; Christensen, O.B.; Lucas-Picher, P. On the need for bias correction of regional climate change projections of temperature and precipitation. Geophys. Res. Lett. 2008, 35, L20709. [CrossRef]

4. Teutschbein, C.; Seibert, J. Regional Climate Models for Hydrological Impact Studies at the Catchment Scale: A Review of Recent Modeling Strategies. Geogr. Compass 2010, 4, 834-860. [CrossRef]

5. Cardell, M.F.; Romero, R.; Amengual, A.; Homar, V.; Ramis, C. A quantile-quantile adjustment of the EURO-CORDEX projections for temperatures and precipitation. Int. J. Clim. 2019, 39, 2901-2918. [CrossRef]

6. Allen, M.; Kettleborough, J.; Stainforth, D.A. Model error in weather and climate forecasting. Weather Clim. 2006, 275-294. [CrossRef]

7. Mearns, L.O.; Arritt, R.; Binner, S.; Bukovsky, S.M.; McGinnis, S.; Sain, S.; Caya, D.; Correia, J.; Flory, D.; Gutowski, W.; et al. The North American Regional Climate Change Assessment Program: Overview of Phase I Results. Bull. Am. Meteorol. Soc. 2012, 93, 1337-1362.

8. Cannon, A.J.; Sobie, S.R.; Murdock, T.Q. Bias Correction of GCM Precipitation by Quantile Mapping: How Well Do Methods Preserve Changes in Quantiles and Extremes? Journal of Climate 2015, 28, 6938-6959. [CrossRef]

9. Murphy, J. An Evaluation of Statistical and Dynamical Techniques for Downscaling Local Climate. J. Clim. 1999, 12, 2256-2284. [CrossRef]

10. Wilby, R.L.; Wigley, T.M.L. Precipitation predictors for downscaling: Observed and general circulation model relationships. Int. J. Climatol. 2000, 20, 641-661. [CrossRef]

11. Ahmed, K.F.; Wang, G.; Silander, J.; Wilson, A.M.; Allen, J.M.; Horton, R.; Anyah, R. Statistical downscaling and bias correction of climate model outputs for climate change impact assessment in the U.S. northeast. Glob. Planet. Chang. 2013, 100, 320-332. [CrossRef] 
12. Samuelsson, P.; Jones, C.G.; Willén, U.; Ullerstig, A.; Gollvik, S.; Hansson, U.; Jansson, C.; Kjellströ, E.; Nikilun, G.; Wyser, K. The Rossby Centre Regional Climate model RCA3: Model description and performance. Tellus A Dyn. Meteorol. Oceanogr. 2011, 63, 4-23. [CrossRef]

13. Strandberg, G.; Bärring, L.; Hansson, U.; Jansson, C.; Jones, C.; Kjellström, E.; Kupiainen, M.; Nikulin, G.; Samuelsson, P.; Ullerstig, A. CORDEX scenarios for Europe from the Rossby Centre regional climate model RCA4. Rep. Meteorol. Climatol. 2014, 116, 84.

14. Malhi, Y.; Wright, J. Spatial patterns and recent trends in the climate of tropical rainforest regions. Philos. Trans. R. Soc. Lond Ser. B Biol. Sci. 2004, 359, 311-329. [CrossRef]

15. Terink, W.; Hurkmans, R.T.W.L.; Torfs, P.J.J.F.; Uijlenhoet, R. Bias correction of temperature and precipitation data for regional climate model application to the Rhine basin. Hydrol. Earth Syst. Sci. Discuss 2009, 6, 5377-5413. [CrossRef]

16. Fang, G.H.; Yang, J.; Chen, Y.N.; Zammit, C. Comparing bias correction methods in downscaling meteorological variables for a hydrologic impact study in an arid area in China. Hydrol. Earth Syst. Sci. 2015, 19, 2547-2559. [CrossRef]

17. Moore, K.; Pierson, D.; Pettersson, K.; Schneiderman, E.; Samuelsson, P. Effects of warmer world scenarios on hydrologic inputs to Lake Mälaren, Sweden and implications for nutrient loads. Hydrobiologia 2008, 599, 191-199. [CrossRef]

18. Rasmussen, J.; Sonnenborg, T.O.S.; Stisen, L.P.; Seaby, B.S.B.; Christensen, H.K. Climate change effects on irrigation demands and minimum stream discharge: Impact of bias-correction method. Hydrol. Earth Syst. Sci. 2012, 16, 4675-4691. [CrossRef]

19. Lenderink, G.; Buishand, A.; Deursen, W.V. Estimates of future discharges of the river Rhine using two scenario methodologies: Direct versus delta approach. Hydrol. Earth Syst. Sci. 2007, 11, 1145-1159. [CrossRef]

20. Schmidli, J.; Frei, C.; Vidale, P.L. Downscaling from GCM precipitation: A benchmark for dynamical and statistical downscaling methods. Int. J. Climatol. 2006, 26, 679-689. [CrossRef]

21. Leander, R.; Buishand, T.A.; Van den Hurk, B.J.J.M.; De Wit, M.J.M. Estimated changes in flood quantiles of the river Meuse from resampling of regional climate model output. J. Hydrol. 2008, 351, 331-343. [CrossRef]

22. Block, P.J.; Souza Filho, F.A.; Sun, L.; Kwon, H.H. A Streamflow Forecasting Framework using Multiple Climate and Hydrological Models. Jawra. Am. Water Resour. Assoc. 2009, 45, 828-843. [CrossRef]

23. Sun, F.; Roderick, M.L.; Lim, W.H.; Farquhar, G.D. Hydroclimatic projections for the Murray-Darling Basin based on an ensemble derived from Intergovernmental Panel on Climate Change AR4 climate models. Water Resour. Res. 2011, 47, 1-14. [CrossRef]

24. Piani, C.; Haerter, J.O.; Coppola, E. Statistical bias correction for daily precipitation in regional climate models over Europe. Theor. Appl. Climatol. 2010, 99, 187-192. [CrossRef]

25. Jakob Themeßl, M.; Gobiet, A.; Leuprecht, A. Empirical-statistical downscaling and error correction of daily precipitation from regional climate models. Int. J. Climatol. 2011, 31, 1530-1544. [CrossRef]

26. Gudmundsson, L.; Bremnes, J.B.; Haugen, J.E. Engen-Skaugen Technical Note: Downscaling RCM precipitation to the station scale using statistical transformations: A comparison of methods. Hydrol. Earth Syst. Sci. 2012, 16, 3383-3390.

27. Teutschbein, C.; Seibert, J. Bias correction of regional climate model simulations for hydrological climate-change impact studies: Review and evaluation of different methods. J. Hydrol. 2012, 456-457, 12-29. [CrossRef]

28. Chen, J.; Brissette, F.P.; Chaumont, D.; Braun, M. Finding appropriate bias correction methods in downscaling precipitation for hydrologic impact studies over North America. Water Resour. Res. 2013, 49, 4187-4205. [CrossRef]

29. Rojas, R.; Feyen, L.; Dosio, A.; Bavera, D. Improving pan-European hydrological simulation of extreme events through statistical bias correction of RCM-driven climate simulations. Hydrol. Earth Syst. Sci. 2011, 15, 2599-2620. [CrossRef]

30. Maraun, D.; Wetterhall, F.; Ireson, A.M.; Chandler, R.E.; Kendon, E.J.; Widmann, M.; Brienen, S.; Rust, H.W.; Sauter, T.; Themeßl, M.; et al. Precipitation downscaling under climate change: Recent developments to bridge the gap between dynamical models and the end user. Rev. Geophys. 2010, 48, RG3003. [CrossRef]

31. Maraun, D. Bias Correction, Quantile Mapping, and Downscaling: Revisiting the Inflation Issue. J. Clim. 2013, 26, 2137-2143. [CrossRef] 
32. Boé, J.; Terray, L.; Habets, F.; Martin, E. Statistical and dynamical downscaling of the Seine basin climate for hydro-meteorological studies. Int. J. Climatol. 2007, 27, 1643-1655. [CrossRef]

33. Hempel, S.; Frieler, K.; Warszawski, L.; Schewe, J.; Piontek, F. A trend-preserving bias correction and amp;ndash; the ISI-MIP approach. Earth Syst. Dyn. 2013, 4, 219-236. [CrossRef]

34. Maurer, E.P.; Pierce, D.W. Bias correction can modify climate model simulated precipitation changes without adverse effect on the ensemble mean. Hydrol. Earth Syst. Sci. 2014, 18, 915-925. [CrossRef]

35. Endris, H.S.; Omondi, P.; Jain, S.; Lennard, C.; Hewitson, B.; Chang'a, L.; Awange, J.L.; Dosio, A.; Ketiem, P.; Nikulin, G.; et al. Assessment of the Performance of CORDEX Regional Climate Models in Simulating East African Rainfall. J. Clim. 2013, 26, 8453-8475. [CrossRef]

36. Kisembe, J.; Favre, A.; Dosio, A.; Lennard, L.; Sabiiti, G.; Nimusiima, A. Evaluation of rainfall simulations over Uganda in CORDEX regional climate models. Theor. Appl. Climatol. 2019, 137, 1117-1134. [CrossRef]

37. Ongoma, V.; Chen, H.; Gao, C. Evaluation of CMIP5 twentieth century rainfall simulation over the equatorial East Africa. Theor. Appl. Climatol. 2019, 135, 893-910. [CrossRef]

38. Ayugi, B.; Tan, G.; Gnitou, G.T.; Ojara, M.; Ongoma, V. Historical evaluations and simulations of precipitation over East Africa from Rossby centre regional climate model. Atmos. Res. 2020, 232, 104705. [CrossRef]

39. Kimani, M.; Hoedjes, J.; Su, Z. An Assessment of Satellite-Derived Rainfall Products Relative to Ground Observations over East Africa. Remote Sens. 2017, 9, 430. [CrossRef]

40. Kimani, M.; Hoedjes, J.; Su, Z. Bayesian Bias Correction of Satellite Rainfall Estimates for Climate Studies. Remote Sens. 2018, 10, 1074. [CrossRef]

41. Ayugi, B.; Tan, G.; Ullah, W.; Boiyo, R.; Ongoma, V. Inter-comparison of remotely sensed precipitation datasets over Kenya during 1998-2016. Atmos. Res. 2019, 225, 96-109. [CrossRef]

42. Indeje, M.; Semazzi, F.H.M.; Xie, L.; Ogallo, L.J. Mechanistic Model Simulations of the East African Climate Using NCAR Regional Climate Model: Influence of Large-Scale Orography on the Turkana Low-Level Jet. J. Clim. 2001, 14, 2710-2724. [CrossRef]

43. Mumo, L.; Yu, J.; Fang, K. Assessing Impacts of Seasonal Climate Variability on Maize Yield in Kenya. Int. J. Plant Prod. 2018, 12, 297-307. [CrossRef]

44. Kottek, M.; Grieser, J.; Beck, C.; Rudolf, B.; Rubel, F. World Map of Köppen-Geiger Climate Classification Main climates. Meteorology 2006, 15, 256-263.

45. Ongoma, V.; Chen, H. Temporal and spatial variability of temperature and precipitation over East Africa from 1951 to 2010. Meteorol. Atmos. Phys. 2017, 129, 131-144. [CrossRef]

46. Ayugi, B.O.; Wen, W.; Chepkemoi, D. Analysis of Spatial and Temporal Patterns of Rainfall Variations over Kenya. Environ. Earth Sci. 2016, 6, 69-83.

47. Ayugi, B.O.; Tan, G.; Ongoma, V.; Mafuru, K.B. Circulations Associated with Variations in Boreal Spring Rainfall over Kenya. Earth Syst. Environ. 2018, 2, 421-434. [CrossRef]

48. Mumo, L.; Yu, J.; Ayugi, B. Evaluation of spatiotemporal variability of rainfall over Kenya from 1979 to 2017. J. Atmos. Sol. -Terr. Phys. 2019, 194, 105097. [CrossRef]

49. King'uyu, S.M.; Ogallo, L.A.; Anyamba, E.K. Recent Trends of Minimum and Maximum Surface Temperatures over Eastern Africa. J. Clim. 2000, 13, 2876-2886. [CrossRef]

50. Ongoma, V.; Chen, H.; Gao, C.; Sagero, P.O. Variability of temperature properties over Kenya based on observed and reanalyzed datasets. Theor. Appl. Climatol. 2018, 133, 1175-1190. [CrossRef]

51. Ayugi, B.O. Tan G Recent trends of surface air temperatures over Kenya from 1971 to 2010. Meteorol. Atmos. Phys. 2019, 131, 1401-1413. [CrossRef]

52. Hastenrath, S.; Polzin, D.; Mutai, C. Circulation Mechanisms of Kenya Rainfall Anomalies. J. Clim. 2011, 24, 404-412. [CrossRef]

53. Teutschbein, C.; Seibert, J. Is bias correction of regional climate model (RCM) simulations possible for non-stationary conditions? Hydrol. Earth Syst. Sci. 2013, 17, 5061-5077. [CrossRef]

54. Stensrud, D.J. Parameterization Schemes; Cambridge University Press: Cambridge, UK, 2007.

55. Harris, I.; Jones, P.D.; Osborn, T.J.; Lister, D.H. Updated high-resolution grids of monthly climatic observations-The CRU TS3.10 Dataset. Int. J. Climatol. 2014, 34, 623-642. [CrossRef]

56. Klemeš, V. Operational testing of hydrological simulation models. Hydrol. Sci. J. 1986, 31, 13-24. [CrossRef]

57. Yang, W.; Seager, R.; Cane, M.A.; Lyon, B. The Rainfall Annual Cycle Bias over East Africa in CMIP5 Coupled Climate Models. J. Clim. 2015, 28, 9789-9802. [CrossRef] 
58. Nicholson, S.E. Climate and climatic variability of rainfall over eastern Africa. Rev. Geophys. 2017, 55, 590-635. [CrossRef]

59. Camberlin, P.; Okoola, R.E. The onset and cessation of the 'long rains' in eastern Africa and their interannual variability. Theor. Appl. Climatol. 2003, 75, 43-54. [CrossRef]

60. Ogwang, B.A.; Chen, H.; Li, X.; Gao, C. The Influence of Topography on East African October to December Climate: Sensitivity Experiments with RegCM4. Adv. Meteorol. 2014, 2014, 1-14.

61. Eden, J.M.; Widmann, M.; Grawe, D.; Rast, S. Skill, Correction, and Downscaling of GCM-Simulated Precipitation. J. Clim. 2012, 25, 3970-3984. [CrossRef]

62. Teng, J.; Potter, N.; Chiew, F.; Zhang, L.; Wang, B.; Vaze, J.; Evans, J. How does bias correction of regional climate model precipitation affect modelled runoff? Hydrol. Earth Syst. Sci. 2015, 19, 711-728. [CrossRef]

63. Rowell, D.P.; Booth, B.B.B.; Nicholson, S.E.; Good, P. Reconciling Past and Future Rainfall Trends over East Africa. J. Clim. 2015, 28, 9768-9788. [CrossRef]

64. Tierney, J.E.; Ummenhofer, C.C.; De Menocal, P.B. Past and future rainfall in the Horn of Africa. Sciences. Advances 2015, 1, e1500682. [CrossRef]

65. Ongoma, V.; Chen, H.; Gao, C. Projected changes in mean rainfall and temperature over East Africa based on CMIP5 models. Int. J. Climatol. 2018, 38, 1375-1392. [CrossRef]

66. Strandberg, G.; Bärring, L.; Hansson, U.; Jansson, C.; Jones, C.; Kjellström, E.; Kupiainen, M.; Nikulin, G.; Samuelsson, P.; Ullerstig, A. Projected Changes in Mean and Extreme Precipitation in Africa under Global Warming. Part II: East Africa. J. Clim. 2011, 24, 3718-3733.

67. Funk, C.; Husak, G.; Michaelsen, J.; Shukla, S.; Hoell, A.; Lyon, B.; Hoeling, M.P.; Liebmann, B.; Zhang, T.; Verdin, J.; et al. Predicting East African spring droughts using Pacific and Indian Ocean sea surface temperature indices. Hydrol. Earth Syst. Sci. 2014, 18, 4965-4978. [CrossRef]

68. Liebmann, B.; Hoerling, M.P.; Funk, C.; Bladé, I.; Dole, R.M.; Allured, D.; Quan, X.; Pegion, P.; Eischeid, J.K. Understanding Recent Eastern Horn of Africa Rainfall Variability and Change. J. Clim. 2014, 27, 8630-8645. [CrossRef]

69. Sillmann, J.; Kharin, V.; Zhang, X.; Zwiers, F. Climate extremes indices in the CMIP5 multimodel ensemble: Part 1. Model evaluation in the present climate. J. Geophys. Res. Atmos. 2013, 118, 1716-1733. [CrossRef]

70. Pielke Sr, R.A.; Wilby, R.; Niyogi, D.; Hossain, F.; Dairuku, K.; Adegoke, J.; Kallos, G.; Seastedt, T.; Suding, K. Dealing with complexity and extreme events using a bottom-up, resource-based vulnerability perspective. In Extreme Events and Natural Hazards: The Complexity Perspective; Geophys_Monogr-Ser; American Geophysical Union: Washington, DC, USA, 2012; Volume 196, pp. 345-359.

71. Ehret, U.; Zehe, E.; Wulfmeyer, V.; Warrach-Sagi, K.; Liebert, J. HESS Opinions 'Should we apply bias correction to global and regional climate model data? Hydrol. Earth Syst. Sci. 2012, 16, 3391-3404. [CrossRef]

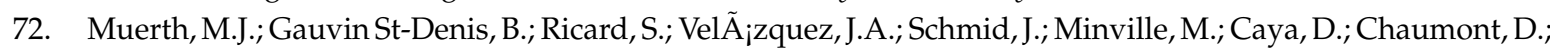
Ludwig, R.; Turcotte, R. On the need for bias correction in regional climate scenarios to assess climate change impacts on river runoff. Hydrol. Earth Syst. Sci. 2013, 17, 1189-1204. [CrossRef]

73. Pielke Sr, R.A.; Wilby, R.L. Regional climate downscaling: What's the point? EOS Trans. Am. Geophys. Union 2012, 93, 52-53. [CrossRef]

74. Füssel, H.M. Review and Quantitative Analysis of Indices of Climate Change Exposure, Adaptive Capacity, Sensitivity, and Impacts; World Bank: Washington, DC, USA, 2010.

75. O'brien, K.A.; Eriksen, S.; Nygaard, L.P.; Schjolden, A.N. Why different interpretations of vulnerability matter in climate change discourses. Clim. Policy 2007, 7, 73-88. [CrossRef]

(C) 2020 by the authors. Licensee MDPI, Basel, Switzerland. This article is an open access article distributed under the terms and conditions of the Creative Commons Attribution (CC BY) license (http://creativecommons.org/licenses/by/4.0/). 